\title{
Article \\ Sound Absorbing and Insulating Low-Cost Panels from End-of-Life Household Materials for the Development of Vulnerable Contexts in Circular Economy Perspective
}

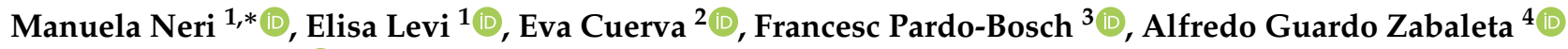 \\ and Pablo Pujadas 2 (D) \\ 1 Department of Mechanical and Industrial Engineering, University of Brescia, via Branze 38, \\ 25121 Brescia, Italy; elisa.levi@unibs.it \\ 2 Department of Project and Construction Engineering, Escola Tècnica Superior d'Enginyers Industrials de \\ Barcelona (ETSEIB), Universitat Politècnica de Catalunya (UPC), Av. Diagonal 647, 08028 Barcelona, Spain; \\ eva.cuerva@upc.edu (E.C.); pablo.pujadas@upc.edu (P.P.) \\ 3 Department of Project and Construction Engineering, Escola Superior d'Enginyeries Industrial, \\ Aeroespacial yi Audiovisual de Terrassa, Universitat Politècnica de Catalunya (UPC), Carrer de Colom 15, \\ 08222 Terrassa, Spain; francesc.pardo@upc.edu \\ 4 Centre de Diagnòstic Industrial i Fluidodinàmica (UPC CDIF), Escola Tècnica Superior d'Enginyers \\ Industrials de Barcelona (ETSEIB), Universitat Politècnica de Catalunya (UPC), Av. Diagonal 647, \\ 08028 Barcelona, Spain; alfredo.guardo-zabaleta@upc.edu \\ * Correspondence: manuela.neri@unibs.it
}

\section{check for} updates

Citation: Neri, M.; Levi, E.; Cuerva, E.; Pardo-Bosch, F.; Zabaleta, A.G.; Pujadas, P. Sound Absorbing and Insulating Low-Cost Panels from End-of-Life Household Materials for the Development of Vulnerable Contexts in Circular Economy Perspective. Appl. Sci. 2021, 11, 5372. https://doi.org/10.3390/app 11125372

Academic Editor: Luís Picado Santos

Received: 3 May 2021

Accepted: 2 June 2021

Published: 9 June 2021

Publisher's Note: MDPI stays neutral with regard to jurisdictional claims in published maps and institutional affiliations.

Copyright: (c) 2021 by the authors. Licensee MDPI, Basel, Switzerland. This article is an open access article distributed under the terms and conditions of the Creative Commons Attribution (CC BY) license (https:// creativecommons.org/licenses/by/ $4.0 /)$.

\begin{abstract}
From a construction point of view, neighborhoods with residents living at or below the poverty threshold are characterized by low energy efficiency buildings, in which people live in acoustic discomfort with no viable options for home improvements, as they usually can not afford the materials and labor costs associated. An alternative to this is to use low-cost insulating elements made of non-conventional materials with acceptable acoustic properties. Given that household materials at their end-of-life (EoLHM) are free of costs and available also to the more disadvantaged population, they can be used to build acoustic panels for such contexts. This approach embraces several benefits since it reduces the amount of waste produced, the footprint deriving from the extraction of new raw materials and, by highlighting the potential of the EoLHM, discourages the abandonment of waste. In this paper, the acoustic properties of EoLHM, such as cardboard, egg-cartons, clothes, metal elements and combinations of them, are investigated by means of the impedance tube technique. The measured sound absorption coefficient and transmission loss have shown that EoLHM can be used for the realization of acoustic panels. However, since none of the analyzed materials shows absorbing and insulating properties at the same time, EoLHM must be wisely selected. This innovative approach supports the circular economy and the improvement for the living condition of low-income households.
\end{abstract}

Keywords: household end-of-life materials; building retrofitting; sound insulation; sound absorption; vulnerable houses; circular economy; egg-box; cardboard; textile waste; reuse

\section{Introduction}

The Sustainable Development Goals are a universal call embraced by all Member States of the United Nation in 2015 for eradicating poverty and protecting the environment. According to the call, for improving the living condition on a global scale, economy and social aspects must go hand-in-hand. For this reason, issues such as education, health, social protection, job opportunities, climate change and environmental protection must be taken into account through global, local and people actions [1]. Among the 17 Goals, number 11 deals with sustainable cities and communities, and it requires to ensure access for everyone to adequate, safe and affordable housing and basic services. Indeed, it is estimated that by 
2030 the $60 \%$ of the world's population will live in cities that account for about the $70 \%$ of global carbon emission and $60 \%$ of resource use. The rapid urbanization that the world has been facing since 2007 is resulting in air pollution, unplanned urbanization, inadequate services and infrastructures. The growth and development of cities must be controlled, so to guarantee cities inclusive, safe, resilient and sustainable.

Since people with similar socioeconomic status tend to cluster in the same urban areas disadvantaged contexts can be easily identified in the urban fabric: in these places, the vulnerable population lives and it consists of refugees, migrants, elderly persons, people with disabilities and children [1]. In these specific contexts, people live below the threshold of poverty, and sometimes in conditions of great discomfort. This phenomenon is responsible of inequalities and it has been identified in several European cities, as in the case of Barcelona [2,3]. Between 2001 and 2011, in the city of Barcelona the migrant population increased from about $5 \%$ to $17 \%$, and the new-low income immigrants reside mostly either in the historical center, usually on degraded 19th century buildings, or in peripheral districts characterized by poor quality houses built in the 1960s and in the 1970s [2]. In the case of the historical center, dwellings are in some cases small, overcrowded and lacking of openings with consequent insufficient natural light and poor air quality. When present, windows are crumbling and do not guarantee adequate acoustic insulation. Since many of these neighborhoods are also touristic destinations with noisy anthropic activities also during the night-time, the aspect related to the sound quality of dwellings should not be underestimated.

The urban environment is characterized by multiple simultaneous sounds due to transportation, industry and neighbors. When the sound pressure level exceeds a certain value it is perceived as noise and even if sound perception is subjective, noise control is very important. The exposure to excessive and prolonged levels of noise affects people's well-being, behavior, productivity, mental and physical health, with negative consequences such as sleep disturbances, stress, irritability and other health issues [2,4-6]. However, noise pollution and acoustic discomfort in buildings are not limited to disadvantaged neighborhoods. To depict the acoustic situation, the European Union, through the Environmental Noise directive [7], has requested to map the noise pollution sources and to define an action plan to reduce the effects on the population. It is estimated that $40 \%$ of the population does not experience acoustic well-being because of noise from neighbors and traffic [5], and the $65 \%$ of Europeans living in major urban areas are exposed to highnoise levels [8]. If in virtuous contexts the improvement of the indoor acoustic comfort is possible, in disadvantaged contexts this task is much more difficult to achieve. In fact, these interventions require specialized personnel and expensive insulating/absorbing acoustic solutions. Acoustic panels must be aesthetics, safe, acoustically efficient, easy to install and maintain, resistant to wear and environmental factors. Although inexpensive acoustic materials can be found on the market, in disadvantaged contexts they can not be easily purchased because people have little or no financial resources. An alternative can be the realization of no-cost panels featuring acoustic properties.

While on the one hand there is growing attention to the well-being of people, on the other it is necessary to define actions aimed at protecting the environment, optimizing the system that provides us with the raw materials necessary to make the products, and which houses the waste. To lighten the load on the environment, it is necessary to use raw materials in a conscious way, for example, by extending the life of the products as much as possible. Additionally, since many materials still possess exploitable properties when they are discarded, they can be reused for other purposes. This model is called Circular Economy (CE) which is in contrast to the linear economy model. In the linear economy model, the raw material is extracted, processed to make the product that, at the end of its life, is discarded. The circular economy model, on the other hand, is based on the 7R principle: reduce, reuse, recycle, repair, replace, recovery, remanufacture as shown in Figure 1. 


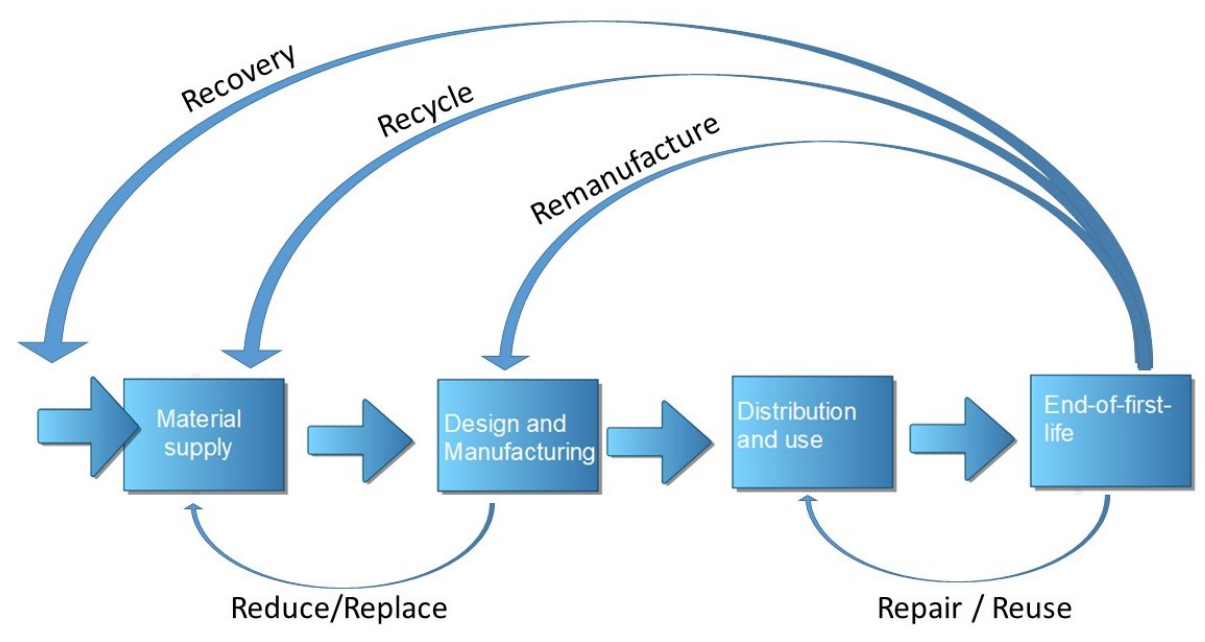

Figure 1. Comparison between circular and linear economy models [9].

With a view to the circular economy and sustainable cities, household end-of-life materials (EoLHM), such as clothes or packaging, could be reused to realize acoustic panels. EoLHM can be defined as household waste materials which still possess exploitable properties, thus making them suitable for reuse. Many EoLHM still have properties when discharged and are largely available: for example, the estimated yearly global production is about 241 million tons for cardboard and paper packaging [10,11], 380,000 million tons for plastic packaging [12], and 92 million tons for textile waste [13] of which only the $12 \%$ is recycled [14]. The large availability of EoLHM and the problems related to recycling can support the approach of converting them into acoustic panels: as suggested in [15], this avoids the generation of waste, reduces the footprint due to raw materials extraction, and makes them accessible also to vulnerable population that can not afford commercial acoustic materials. Moreover, since EoLHM are largely available, this approach could incentive buildings renovation and facilitate the achievement of the energy and environmental international goals set by the European Parliament $[16,17]$.

The study presented in this paper explores the possibility of converting EoLHM into panels featuring interesting acoustic properties, and it is focused mainly on those EoLHM that can be reused without any type of processing so that they are directly available to lowincome households. Indeed, any treatment would entail costs that would affect end-users and, consequently, the vulnerable population may not be able to afford them. Specifically, the aim of the experimental analysis presented in this paper is to understand which EoHLM can be used to make acoustic panels of limited thickness, and how these materials can be assembled to meet both sound insulation and sound absorption requirements. Since the panels are intended for the most disadvantaged population, they must be easy to be assembled and installed, so that these people, once trained, can collect the necessary EoLHM and assemble the panels independently. The first part of the study addresses the state of the art regarding the reuse of EoLHM to realize acoustic panels. There are several studies in the literature that address the recycling of these materials, but only a limited number analyzes their possible reuse. This highlights that the approach proposed in this paper is quite innovative. In the second part of the paper, EoHLM suitable for low-cost acoustic insulation panels for indoor comfort improvement are investigated by means of experimental tests performed with a 4-microphone impedance tube technique. Five sets of samples have been tested. In the first set of samples, the acoustic performance of egg-cartons has been evaluated. The second set of samples consists in egg-cartons coupled with fibrous materials and metal elements. In the third set of samples, cardboard has been 
featured. Finally, in the fourth and fifth sets of samples, the acoustic properties of different fabrics coupled with egg-cartons and metal elements have been evaluated.

\section{Theoretical Background}

When a sound wave with a certain acoustic power $W_{i}$ impinges a wall-partition, its energy is divided into three components. One portion of the power is reflected back $\left(W_{r}\right)$, while another portion $\left(W_{a}\right)$ is able to pass through the surface of the material. The energy that passes through the surface can be divided into two components $W_{d}$ and $W_{t}$. The component $W_{d}$ represents the part of the absorbed energy actually converted into heat due to the internal friction and viscoelastic effects. The component $W_{t}$ represents the portion of the energy that passes through the partition and it is related to the power transmitted through the wall. The relation among incident, reflected and absorbed power is

$$
W_{i}=W_{r}+W_{a}=W_{r}+W_{d}+W_{t}
$$

as depicted in Figure 2. By dividing the single components for the incident power $W_{i}$, the sound reflection coefficient, the sound dissipation coefficient $\delta$, and the sound transmission coefficient $\tau$ are defined:

$$
\begin{aligned}
& r=W_{r} / W_{i} \\
& \delta=W_{d} / W_{i} \\
& \tau=W_{t} / W_{i}
\end{aligned}
$$

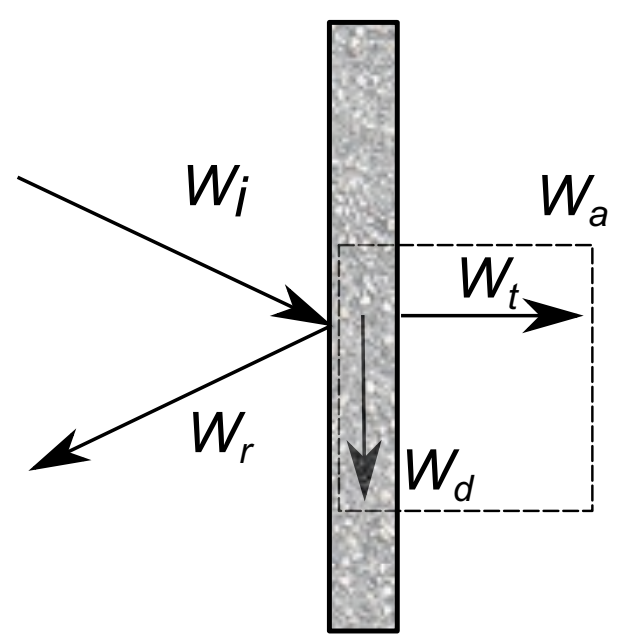

Figure 2. Decomposition of a sound wave $W_{i}$ impinging a wall into its reflected $W_{r}$, dissipated $W_{d}$ and transmitted $W_{t}$ components. The sum of the dissipated and transmitted components represents the absorbed $W_{a}$ component.

Building acoustics usually investigates the frequency range going from $100 \mathrm{~Hz}$ to $3150 \mathrm{~Hz}$ [18]. The reason of the $100 \mathrm{~Hz}$ lower frequency limit is that, in general, the first speech tones range between $100 \mathrm{~Hz}$ and $125 \mathrm{~Hz}$ for men, and they are an octave higher for women. As concerns the emission due to traffic noise, the encompassed frequency range is $125-2500 \mathrm{~Hz}$ and depends on the vehicles' speed. The two main properties to be considered for indoor acoustic comfort are the apparent sound absorption coefficient $\alpha$ and the sound transmission loss $T L$. The apparent absorption coefficient is defined as:

$$
\alpha=1-r
$$

and it represents the portion of incident energy absorbed (or not reflected) by the partition. In practice, sound absorbing materials and structures reduce the possibility of multiple reflections and are able to 'clean' the indoor acoustic environment from the annoying effects of reverberation. Sound absorbing materials and structures can be classified as porous 
materials, acoustic resonators (Helmholtz resonators that include perforated and microperforated panels respectively), vibrating panels and mixed systems (Figure 3).

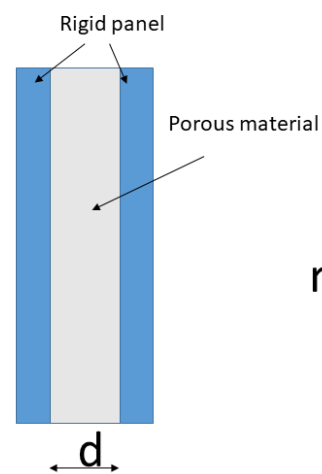

a)

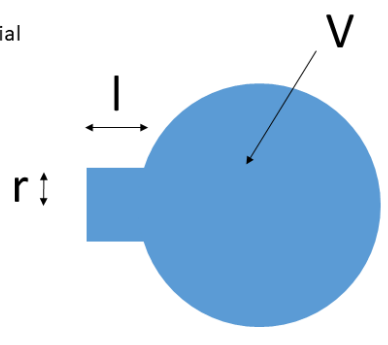

b)

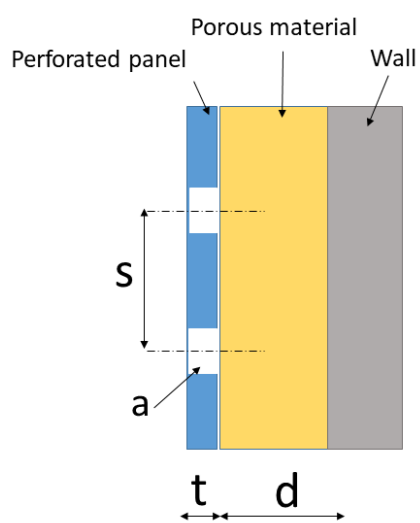

c)

Figure 3. Representation of (a) a double partition made of two rigid leafs with an internal porous layer, (b) Helmholtz resonator and (c) mixed system-multiple resonator.

\subsection{Sound Absorption}

The absorbing performance of a given material depends on the angle of incidence of the sound wave, on the frequency, on the material properties and thickness, and on the surface finishing. The absorption coefficient is usually measured in single reverberation rooms, that allows an evaluation of the absorption properties in diffuse field, or by two or four microphones impedance tubes that evaluate only the properties for a sound wave impinging normally on the sample surface. In spite of this, the impedance tube requires small samples and, for this reason, it is particularly suitable during the research and development phase. To easily compare the properties of different materials, the weighted Noise Reduction Coefficient (NRC) is one of the most used indicators [19].

$$
N R C=\frac{\alpha_{125}+\alpha_{250}+\alpha_{500}+\alpha_{1000}+\alpha_{2000}}{5}
$$

The NRC summarizes the absorption characteristic of a material through a single value ranging between 0 (perfectly reflective material) and 1 (perfectly absorbent material).

\subsubsection{Porous Materials}

This kind of materials is characterized by high porosity, low density and, if possible, a high surface area. Porous materials include fibrous, cellular (foams) and granular materials. The absorption properties depend on a number of parameters including flow resistivity and tortuosity. The dissipation of sound energy is due to three phenomena that are the friction between air and material fibers, the compression and decompression of air, and viscous effects [20,21].

In the literature, several empirical and theoretical models have been proposed for the prediction of porous materials sound absorption. One of the first available models was proposed by Delany-Bazley [22] and requires only the flow resistivity $\sigma$ as an input parameter, but since it neglects the thermal conductive effects, it is accurate in the $0.01<\left(\rho_{0} f / \sigma\right)<1$ range only, where $\rho_{0}$ is the air density and $f$ is the sound frequency [23]. More accurate but, at the same time, more complex models were defined by several authors [24-27]. One of the most popular models was proposed by Johnson-Champoux-Allard (JCA) and takes into account the flow resistivity $\sigma$, open porosity $\phi$, tortuosity $\alpha_{\infty}$, the viscous characteristic length $\Lambda$ and the thermal characteristic length $\Lambda^{\prime}$ [20]. 


\subsubsection{Acoustic Resonators}

A Helmholtz resonator consists of a cavity with one or more holes and necks, as represented in Figure 3b. The air inside the neck behaves like an oscillating piston (mass) while the air in the cavity behaves like an elastic element (spring). When the resonance frequency of the mass-spring system is equal to the frequency of the incident wave, the resonator express its maximum absorption. For these systems, the resonance frequency $f_{0}$ is defined as:

$$
f_{0}=\frac{c_{0}}{2 \pi} \sqrt{\frac{r^{2}}{V\left(l+\frac{\pi}{2 r}\right)}}
$$

where $c_{0}$ is the speed of sound in air, $r$ is the radius of the hole, $V$ is the volume of the cavity and $l$ is the length of the neck. However, Helmholtz resonators do not express any sound absorption outside the resonance frequency region. The transmission loss $T L$ and the absorption coefficient of a Helmholtz resonator are defined as:

$$
\begin{gathered}
T L=-10 \log \left|\frac{p_{t}}{p_{i}}\right|^{2}=20 \log \left|1+\frac{1}{2} \frac{S \rho \rho c_{0}}{S Z}\right| \\
\alpha=1-\left|\frac{p_{t}}{p_{i}}\right|^{2}=\frac{4 c_{0} \rho_{0} \frac{S}{S_{0}} Z_{R e}}{\left(\frac{S}{S_{0}} Z_{R e}+\rho_{0} c_{0}\right)^{2}+\frac{S^{2}}{S_{0}^{2}} Z_{I m}}
\end{gathered}
$$

where $S$ is the cross-sectional area of the neck, $S_{0}$ is the total areas of all necks, $Z$ is the acoustic impedance of the resonator and represent the ratio between pressure amplitude and the particle velocity at the interface of the resonator [28].

\subsubsection{Vibrating Panels}

Another type of sound absorbing mechanism is the one involving vibrating panels placed at a distance from a rigid wall. Vibrating panels are thin, rigid and flat leafs and the absorption mechanism is again of the mass-spring type. The resonance frequency, at which the maximum absorption occurs, is determined as:

$$
f_{0}=60 / \sqrt{\mu^{\prime \prime} d}
$$

where $\mu^{\prime \prime}$ is the mass per unit area of the panel and $d$ is the thickness of the panel as depicted in Figure 3c.

\subsection{Sound Transmission Loss}

The Transmission Loss represents the ability of a structure to block the sound propagation in neighboring ambient and is defined as

$$
T L=10 \cdot \log \frac{1}{\tau}
$$

Materials characterized by a low transmission coefficient have a high $T L$. The sound insulation properties depend mainly on the mass per unit area of the structure, the angle of incidence and the frequency of the impinging wave. Other factors influencing the transmission of the sound are the nature of the partition (single, double), the internal losses and the boundary conditions [29]. The acoustic insulation performance of a homogeneous wall can be divided into four regions as shown in Figure 4. 


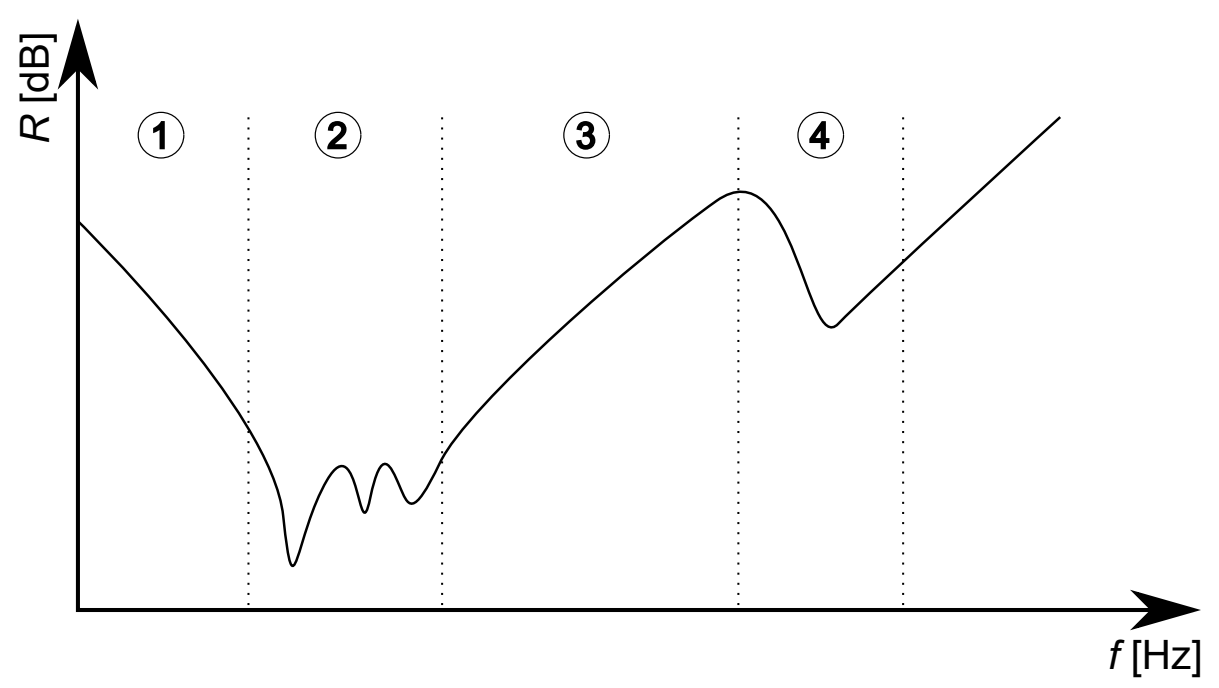

Figure 4. Sound transmission loss of a single panel: (1) stiffness controlled region, (2) resonances region, (3) mass law region, (4) coincidence region.

In the low frequency region, the $T L$ is governed by the material stiffness and it decreases $6 \mathrm{~dB} /$ oct. The behavior of the panel is then dominated by the modes of the specimen, which depend on the elastic and geometric properties of the wall. When the modal density is sufficiently high, the wall behaves according to the mass law [30]. In this region, the transmission loss has a linear trend and increases $6 \mathrm{~dB} /$ oct. The mass-law region is limited by the coincidence effect that occurs when the wavelength of the sound in the air is the same as the wavelength of the bending waves in the partition. In this region the partition does offer a weak opposition to sound propagation. The coincidence frequency $f_{c}$ of a homogeneous board is related to its size, thickness, Young's modulus, and surface density:

$$
f_{c}=\frac{c^{2}}{2 \pi} \sqrt{\frac{\mu^{\prime \prime}}{D}}
$$

where $D$ is the bending stiffness calculated as

$$
D=E \cdot I_{b}
$$

$E$ is the Young modulus, and $I_{b}$ is the moment of inertia. The bending stiffness can be computed also for complex structures, once the Young's modulus and the moment of inertia of the elements are known [31].

The sound insulation of a wall can be significantly increased if it is built as a multiple structure. One common way to increase the sound insulation of a partition, without increasing the mass per unit area, is to build it with two or more layers separated by an air gap, possibly filled by sound absorbing material. In this case the wall behaves like a multiple mass-spring-mass system. When an acoustic wave passes through such a construction, the total transmission factor $\tau_{\text {tot }}$ is:

$$
\tau_{\text {tot }}^{n=N}=\tau_{1} \cdot \tau_{2} \cdot \ldots \cdot \tau_{n}
$$

in which the assumption is that the $N$ layers have a transmission factor $\tau_{n}$. The equation holds at sufficiently high frequency (above the mass-spring-mass frequency $f_{0}$ ), for large enough distances between the layers and when the damping of the gap, in the form of sound absorbing material, is sufficiently high. Below the mass-spring-mass resonance standing waves between the layers modify the transmission factor. The most common case is the one featuring a double wall. If the mass law holds, then the following equation can be applied:

$$
R_{\perp}=20 \log \left(\mu^{\prime \prime} \cdot f\right)-42 \text { for } f<f_{c}
$$


In case of a finite double wall, the sound transmission loss can be computed as:

$$
R_{\perp}^{\text {double }}=20 \log \left[\frac{2 \cdot \pi \cdot f \cdot \mu_{1}^{\prime \prime}}{\left(2 \rho_{0} \cdot c_{0}\right)}\right]+20 \cdot \log \left[\frac{\left(2 \cdot \pi \cdot f \cdot \mu_{2}^{\prime \prime}\right)}{\left(2 \rho_{0} \cdot c_{0}\right)}\right] \text { for } f<f_{c}
$$

The mass law has a lower bound given by the lower mechanical resonance of the system. This resonance corresponds to the mass-spring-mass resonance of the wall, where the air enclosed in the gap acts as a spring, while the walls act like two masses. A two degrees of freedom system has a resonance frequency equal to:

$$
f_{0}=\frac{\pi}{2}\left(\frac{\rho_{0} \cdot c^{2} \cdot\left(\mu_{1}^{\prime \prime}+\mu_{2}^{\prime \prime}\right)}{\left(\mu_{1}^{\prime \prime} \cdot \mu_{2}^{\prime \prime} \cdot h\right)}\right)^{1 / 2}
$$

Below the mass-air-mass frequency the wall behaves like a single wall with a total mass per unit area equal to the sum of the mass per unit areas of the two walls composing the entire wall. As concerns the coincidence effects, the discussion made for single walls also applies to double walls. For double walls, the coincidence frequency is determined by the mass per unit area and thickness of each element, while the $T L$ is higher than that predicted by the mass-law for a single panel of the same mass. As suggested in [32], it can be an advantage to realize the double panel with two panels having different thicknesses to avoid that the coincidence effect takes place at the same frequency.

\subsection{Acoustic Performance of EoLHM in the Literature}

In this section, the acoustic performances reported in the literature of some EoLHM are collected. It is worth noting that the performances of acoustic materials deriving from agriculture have not been analyzed, because they are not directly available to disadvantaged people. Neither organic waste has been analyzed, even if in the literature several studies, such the one presented in [33], can be found.

\subsubsection{Textile Waste}

Textile waste includes clothes, carpets, tablecloths and pieces from the textile sector. In literature, a very recurring classification is between woven (WF) and non-woven (NWF) fabrics: WF are obtained by threading fibers together perpendicularly, whereas NWF are bounded together by using heat, chemical, or mechanical treatment. Textile waste have been widely investigated from the acoustic point of view because they are largely available and their porous structure makes them suitable for acoustic absorption. The sound absorption of NWF waste was investigated in relation to the fiber content and the fiber diameter [34], and NWF shows higher sound reduction than WF [35]. A panel made of waste wool and polyamide fibers was designed in [36], and it presented a sound absorption coefficient equal to 0.91 and $N R C$ equal to 0.56 . The study pointed out that the sound absorption coefficient in the low-frequency range is affected by the thickness, while the volume density affects the absorption properties in the middle-frequency range. Blankets for building roofing and internal walls insulation were realized with polyester fabrics of different sizes and they showed an NRC ranging between 0.54 and 0.74 [37]. The study in [38] investigated the correlation between the humidity content and the transmitted wave through cotton fabric: for moisture content between 0 and $100 \%$, the transmitted wave ranges between $31 \%$ and $7 \%$.

\subsubsection{Cardboard}

According to [39], cardboard panels from the packaging industry present promising acoustic insulation performance but slightly lower than common insulation panels. Cardboard performance intended as the combination of acoustic properties, transportability, lightweight, cost and recyclability was evaluated for several cardboard design options in [40], and honeycomb panels filled with cellulose fiber presented the best performance. To evaluate the conservation status of the beer during transport by trucks, the acoustic 
properties of beer packaging was investigated in [41]. The sound absorption of a cover made of porous sponge and cardboard was 0.58 [42]. In [43], sound absorber obtained by mixing recycled paper and a blowing agent showed a NRC of 0.75 .

\subsubsection{Plastic Bottles and Metal Cans}

Plastic bottles of different sizes $(500 \mathrm{~mL}, 750 \mathrm{~mL}, 1 \mathrm{~L}, 1.25 \mathrm{~L}$ and $2 \mathrm{~L})$ can be easily found on the market [18]. In the literature, bottles have been analyzed mainly from the structural point of view when incorporated in the construction of walls since, if compared to ceramic and concrete blocks, they are faster to build, require less water and cement and do not produce waste [44]. For these reasons, plastic bottles are continuously investigated. According to [45], polyethylene terephthalate-based material shows good sound-absorbing characteristics, especially at high frequencies. Panels made of recycled PET and sheep wool showed an absorption coefficient $\alpha$ higher than 0.7 in the range of $50-5700 \mathrm{~Hz}$ regardless of the humidity content [46]. The sound absorption of light-soft-plastic bottles with net capacity from 7 to $2000 \mathrm{~mL}$ is affected by the capacity in the range of 100 and $1000 \mathrm{~Hz}$ [47]. Plastic bottles are often used to hold materials that lack structural strength. For example, a slightly lower $T L$ than those of traditional construction materials was measured for PET bottles filled with plastic bags [18]. End-of-life PET bottles were incorporated in a wall $12 \mathrm{~cm}$ thick and tests showed a reduction between $29.8 \mathrm{~dB}$ and $55.8 \mathrm{~dB}$ than the wall without bottles [48]. Additionally, the acoustic properties of aluminum cans were investigated [49]: a sandwich panel made of polystyrene, pressed aluminum cans, rockwool and corrugated cardboard showed a better acoustic performance than gypsum panels, but lower than panels made of rock-wool and egg-boxes.

\subsubsection{Egg-Boxes and Trays}

Egg-boxes and trays can be made of different materials such as plastic, recycled paper, cardboard, but what distinguishes them is their shape. For a long time, egg-cartons have been considered good sound absorbing materials, and they have been widely used for this purpose since they are inexpensive, easy-to-install and easily available [50]. However, their acoustic performances have been recently questioned. It was pointed out that egg-boxes provide good sound absorption only at high frequencies, their NRC equal to 0.4 is too low for considering them sound absorbing elements, and the sound absorption coefficient profile is irregular [51]. The experimental tests presented in [52] showed that the sound absorption coefficient of egg-boxes and fruit trays is affected by the material, orientation of the boxes, and by if they are closed or open. Experimental tests showed that egg-cartons can reduce the reverberation time at mid-frequency [53]. In spite of this, researches have been looking for a way to improve their sound performance by coupling them with other materials. A sound absorbent made of egg-boxes pulp showed an optimized NRC equal to 0.5 [54] A non-standardized test method showed that filling egg-boxes with mineral wool blocks a percentage of sound ranging between $14.42 \%$ and $17.71 \%$ depending on the frequency. Egg-boxes were filled with shredded rice straw paper and textile waste [50], and with polyurethane foam [52]. The panels proposed in [50] showed higher sound absorption coefficients than common egg-boxes cartons at all frequencies, and those presented in [52] featured a $N R C$ equal to 0.87 .

\section{Methods}

The review presented in the previous section shows that, even if a limited number of papers investigated the EoLHM acoustic performances, these materials have exploitable properties for the improvement of the indoor acoustic quality. An ideal panel suitable to be used as a façade element posses both good sound absorption and high transmission loss. As concerns the transmission loss, it must be remembered that the final acoustic performance will also depend on the basic wall on which they will be installed. In this study, the acoustic properties of different panels, realized by coupling different EoLHM, are experimentally investigated to understand whether further studies are required. Tests have 
been performed on samples made of easily obtainable EoLHM such as cardboard, textile waste, egg-boxes, metallic elements and their combination. Since the acoustic conditions of the environment in which these panels will be installed are unknown, configurations with high sound absorption coefficient and good $T L$ are considered interesting and worth to be further investigated. Since this analysis is exploratory, the experimental tests have been performed by means of the impedance tube method that requires small samples and gives reproducible results. However, this technique allows the determination of the properties for sound waves impinging normally on the sample surface.

The experimental investigation of the acoustic properties was performed following the standard procedure given by the ASTM E2611 [55] that required the use of a fourmicrophone impedance tube (Figures 5 and 6). This device consists of two tubes of equal internal cross section connected to a test sample holder. Four microphones were placed along the tube (two on either side of the specimen). A source emitting a pink noise was placed at one end of the tube. A multi-channel Fast Fourier Transform (FFT) analyzer acquired the signals captured by the microphones. The second endpoint of the tube could be equipped with an anechoic or a reflecting termination, allowing us to perform the tests with two different boundary conditions. The pressure and particle velocity of the traveling waves and of reflected waves could be determined by means of a MATLAB script implemented on the basis of the E2611 ASTM standard [55]. The frequency range investigated went from $100 \mathrm{~Hz}$ to $3150 \mathrm{~Hz}$.

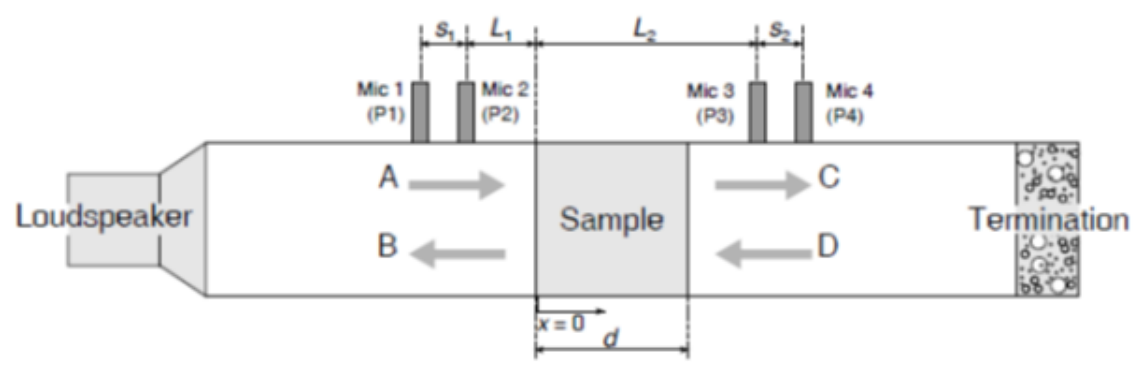

Figure 5. Schematic drawings of a four-microphones impedance tube. A represents the energy emitted by the loudspeaker, $C$ is the component that crosses the sample, $D$ is the component reflected by the termination, and $B$ is the component reflected by the sample and/or that crosses the sample after being reflected by the termination.
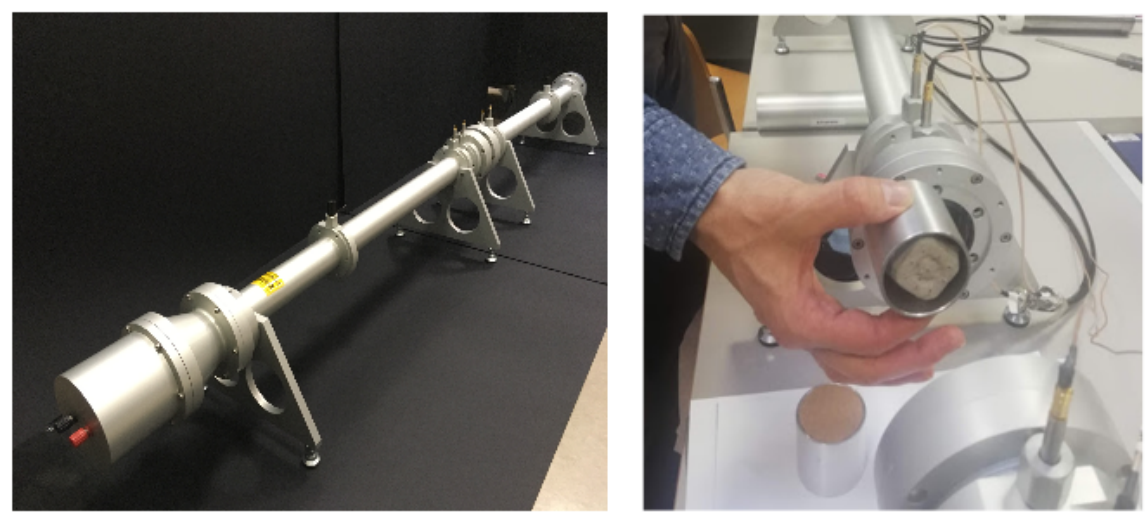

Figure 6. Impedance tube used for the determination of the acoustic properties of EoLHM.

Defining the wave number in air, $k=2 \pi \cdot f / c_{0}$, the traveling and reflected components of the plane wave propagation in the tube (A, B, C and D) can be calculated using the following correlations, once the complex acoustic transfer functions $H_{i, r e f}$ between the $i$ th microphone and the reference microphone are measured:

$$
A=0.5 \times j\left(H_{1, r e f} e^{-j k L_{1}}-H_{2, r e f} e^{-j k\left(L_{1}+s_{1}\right.}\right) / \sin \left(k s_{1}\right)
$$




$$
\begin{aligned}
& B=0.5 \times j\left(H_{2, r e f} e^{+j k\left(L_{1}+s_{1}\right)}-H_{1, r e f} e^{+j k\left(L_{1}\right)}\right) / \sin \left(k s_{1}\right) \\
& C=0.5 \times j\left(H_{3, r e f} e^{+j k\left(L_{2}+s_{2}\right)}-H_{4, r e f} e^{-j k\left(L_{2}\right)}\right) / \sin \left(k s_{2}\right) \\
& D=0.5 \times j\left(H_{4, r e f} e^{-j k L_{2}}-H_{3, r e f} e^{-j k\left(L_{2}+s_{2}\right)}\right) / \sin \left(k s_{2}\right)
\end{aligned}
$$

where, in the case at hand, microphone 1 was selected as the reference microphone. For a given boundary condition, it is possible to determine the acoustic pressure $p$ and the particle velocity $u$ on each face of the specimen using the following equations:

$$
\begin{gathered}
p_{0}=A+B \quad p_{d}=C e^{-j k d}+D e^{+j k d} \\
u_{0}=\frac{A-B}{\rho_{0} c_{0}} \quad u_{d}=\left(C e^{-j k d}-D e^{+j k d}\right) / \rho_{0} c_{0}
\end{gathered}
$$

where $\rho_{0}$ is the density of air. In general, the elements of a transfer matrix $T$, putting into relation pressures and particle velocities at either side of the specimen under test, can be calculated from the acoustic pressures and particle velocities measured during two different experimental sessions performed using an anechoic $(a)$ and a reflecting $(b)$ termination:

$$
[T]=\left[\begin{array}{ll}
T_{11} & T_{12} \\
T_{21} & T_{22}
\end{array}\right]=\left[\begin{array}{ll}
\frac{p_{0 a} u_{d b}-p_{0 b} u_{d a}}{p_{d a} u_{d b}-p_{d b} u_{d a}} & \frac{p_{0 b} p_{d a}-p_{0 a} p_{d b}}{p_{d a} u_{d b}-p_{d b} u_{d a}} \\
\frac{u_{0 a} u_{d b}-u_{0 b} u_{d a}}{p_{d a} u_{d b}-p_{d b} u_{d a}} & \frac{p_{d a} u_{0 b}-p_{d b} u_{0 a}}{p_{d a} u_{d b}-p_{d b} u_{d a}}
\end{array}\right]
$$

The absorption coefficient can be computed as:

$$
\alpha=1-\left|\frac{T_{11}-\rho c T_{21}}{T_{11}+\rho c T_{21}}\right|^{2}
$$

The sound transmission loss $T L$ is expressed as:

$$
T L=20 \times \log _{10}\left|\frac{T_{11}+\left(T_{12} / \rho c\right)+T_{21} \rho c+T_{22}}{2 e^{j k d}}\right|
$$

Samples

The analyzed samples were made putting together different types of EoLHM and are shown in Figures 7 and 8, where the sequence described in the caption starts with the material nearest to the sound source. The layers of the samples were only placed close to and not connected to each other. The samples were $50 \mathrm{~mm}$ long, except for samples 13 and 14 that had a length of $24.2 \mathrm{~mm}$, and sample 26 that was $100 \mathrm{~mm}$ long. The weight of the samples is reported in Table 1. For each sample, three repetitions were performed and the results of the experimental tests were averaged. This has made it possible to evaluate how manual skills influenced the panel acoustic performances.

Table 1. Weight in grams of the samples.

\begin{tabular}{ccccccccccc}
\hline Sample & 3 & 22 & 4 & 5 & 7 & 8 & 13 & 14 & 17 & 26 \\
Weight & 3.6 & 4.19 & 12.63 & 12.63 & 13.33 & 13.33 & 6.47 & 15.4 & 4.36 & 19.31 \\
\hline Sample & 27 & 28 & 29 & 30 & 32 & 33 & 34 & 35 & 36 & \\
Weight & 12.53 & 13.81 & 8.45 & 17.41 & 8.91 & 20.07 & 29.03 & 21.83 & 21.83 & \\
\hline
\end{tabular}




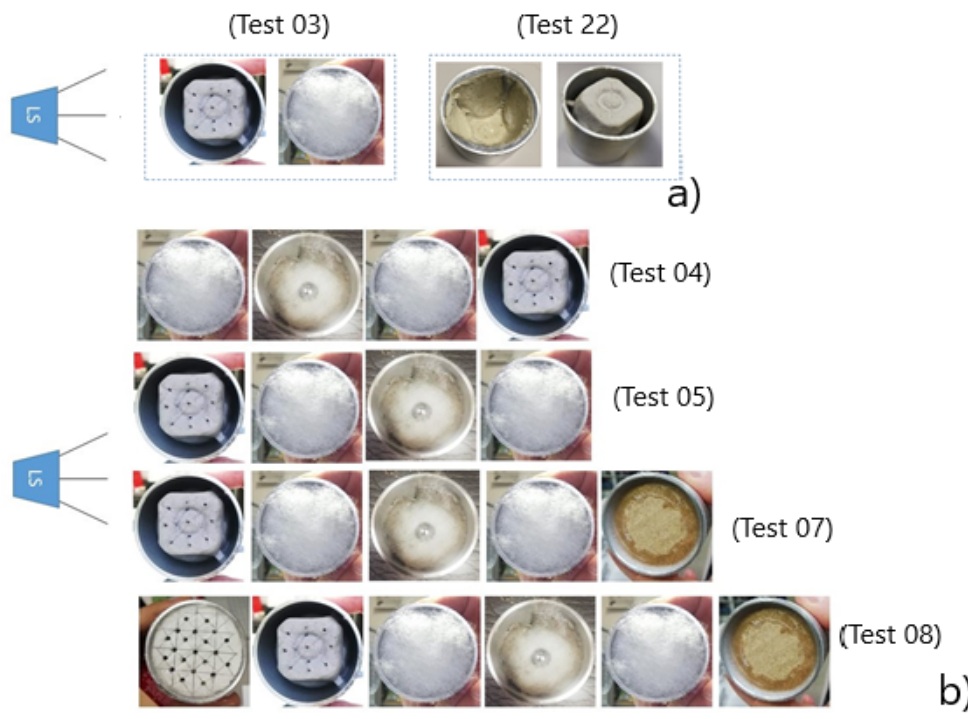

Figure 7. Configurations analyzed with the impedance tube: (a) samples made of eggboxes and polyester, and (b) samples made of egg-box, polyester and a metallic element. Samples 04 and 05 are made of the same elements but in sample 04 the polyester faces the loudspeaker. Sample 08 has an additional perforated cardboard layer.

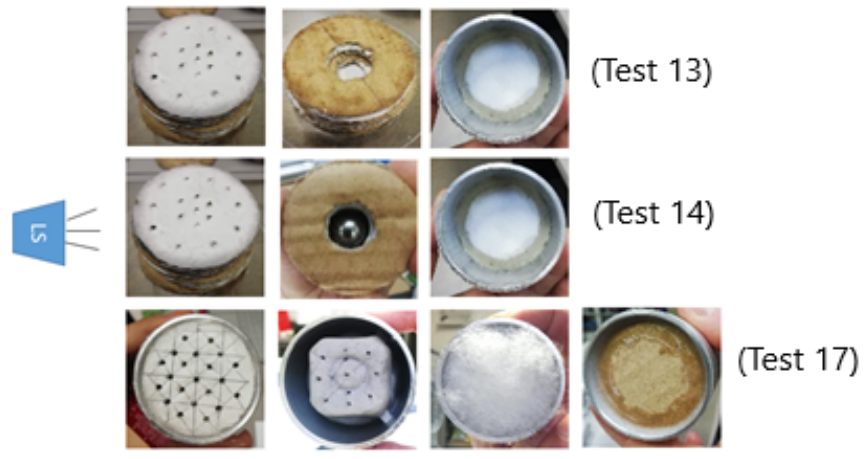

a)

(Test $26: 50 \mathrm{~mm}$ )

(Test 27: $100 \mathrm{~mm}$ )
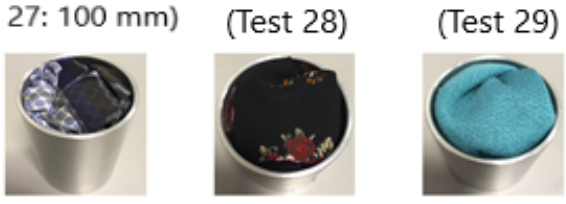

(Test 30)

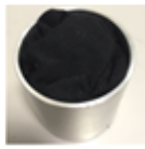

b)

(Test 32)

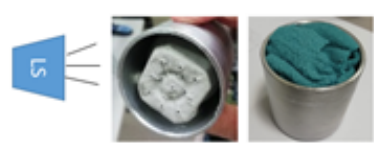

(Test 34)
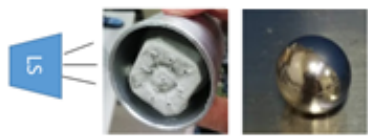
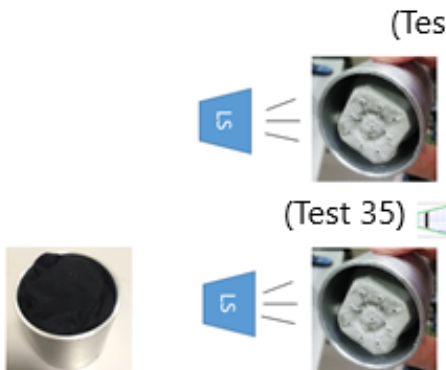

(Test 33)

(Test 35) I (Test 36) ।

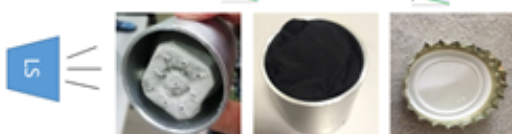

c)

Figure 8. Configurations analyzed with the impedance tube: (a) samples made of several layers of cardboard, (b) samples made of clothes (one fabric at a time), (c) samples made of egg-boxes and clothes. 
Since the acoustic properties of egg-boxes have been questioned in a number of papers $[51,52,56]$, to analyze this aspect, the first set of samples $(03,22)$ was made at least by one egg-carton $2.79 \mathrm{~g}$ in weight made of recycled paper with a density of $355 \mathrm{~kg} / \mathrm{m}^{3}$. In sample 03 , the egg-carton facing the sound source was coupled with loose polyester. The egg-carton was perforated and the holes were less than $1 \mathrm{~mm}$ in diameter. This element was used for realizing the other samples that included egg-boxes, which exception of sample 22 that was made of two not-perforated spaced egg-cartons whose cavity faced the sound source.

To improve the acoustic performance, in the following set of samples $(04,05,07,08)$ the perforated egg-carton was coupled to other EoLHM such as loose polyester, a metallic element and cardboard $197 \mathrm{~kg} / \mathrm{m}^{3}$ in density. The cardboard was made of two external linear boards $0.11 \mathrm{~mm}$ thick and an internal board with 130 flutes $/ \mathrm{m}$. The metal element was a steel sphere with an external diameter of $13 \mathrm{~mm}$, and a weight of $8.95 \mathrm{~g}$.

In particular, samples 04 was made of a box-carton, polyester and a metallic sphere. Sample 05 was similar but had mounted reverse. Samples 07 and 08 were realized to exploit the double panel characteristics. Indeed, a plane wave impinging a double-panel system saw the impedance of the panel closest to the sound source, the impedance of the airspace, the impedance of the second panel, and finally the impedance of the air beyond. The cavity acted as a spring element reducing significantly the TL, especially at higher frequencies. In the cavity the absence of absorptive material contributed to the transmission of sound, while the addition of damping elements such as fibrous materials attenuated the modes of the cavity. For this reason, in samples 07 and 08 cardboard layers were added to create a sort of cavity. In sample 07 , to reduce the permeability, only a cardboard was added on the back of the sample. In sample 08 a perforated layer was added in the front of the sample: the first panel being perforated allowed the passage of a certain quantity of sound and behaved like a Helmholtz resonator.

To characterize cardboard panels, a third set of samples $(13,14,17)$ was prepared. In the last few years, cardboard is largely available at domestic level as a result of the ecommerce. For this reason, highlighting its acoustic properties would encourage its conversion into a building element. Since very sound reflective materials could have a negative impact on acoustic indoor comfort, especially in very crowded ambient such as homes in disadvantaged contexts, the first cardboard layer of the samples was perforated to increase the sound absorption capability. Sample 13 and 14 were made of nine cardboard elements: the first two were perforated, the internal five disks presented a central hole $17 \mathrm{~mm}$ in diameter, while the last two disks were not perforated. In sample 14 a metal sphere was housed in the central layers. The weight of the whole cardboard disk was $0.77 \mathrm{~g}$. Sample 17 was similar to samples 08 except for the presence of the metal sphere and, consequently, the weight of the sample was (13.33 g for sample 08 , and $4.36 \mathrm{~g}$ for sample 17).

In the fourth set of samples (26-32) different fabrics were tested. Samples 26 and 27 were made of cotton, while samples 28,29 and 30 were respectively made of polyester, plush cotton, and viscose. Since the fabrics had no structural strength, it was necessary to fold them inside the impedance tube. This revealed that the installation of the fabrics was strongly influenced by the operator's skills.

In the fifth and last set of samples (32-36), textile waste was coupled with other EoLHMs to improve their insulation performance. To reach a certain degree of stiffness, these samples were realized with a perforated egg-carton facing the sound source. Sample 32 was made of cotton, while the others are made of viscose. By means of tests performed on samples 34-36, the influence of metallic elements was investigated. In particular, a metallic sphere was inserted in sample 34, while a metal cap $1.75 \mathrm{~g}$ in weight and $26 \mathrm{~mm}$ in diameter was included in samples 35 and 36 but only in sample 35 there was contact with the egg-carton. 


\section{Results and Discussion}

The results of the tests described in the previous section are reported in Figures 9-13 showing the sound absorption coefficient $\alpha$ and the transmission loss $T L$ obtained by means of the impedance tube measurements. For each sample, the NRC has been calculated and reported in Table 2.

Table 2. NRC of the samples tested in this paper.

\begin{tabular}{ccccccccccc}
\hline Sample & 3 & 22 & 4 & 5 & 7 & 8 & 13 & 14 & 17 & 26 \\
NRC & 0.49 & 0.45 & 0.56 & 0.48 & 0.54 & 0.60 & 0.45 & 0.44 & 0.58 & 0.84 \\
\hline Sample & 27 & 28 & 29 & 30 & 32 & 33 & 34 & 35 & 36 & \\
NRC & 0.69 & 0.64 & 0.71 & 0.69 & 0.52 & 0.46 & 0.45 & 0.38 & 0.37 & \\
\hline
\end{tabular}

Figure 9 shows that, for samples 03 and 22, the most interesting sound insulation performance was given by sample 22, with a $T L$ following the mass law up to $800 \mathrm{~Hz}$ and then a behavior typical of double walls, with a coincidence frequency around $1800 \mathrm{~Hz}$. Sample 03 was not able to reach the same performances. As regards the absorption coefficient, it was characterized by wide peaks at given frequencies due to holes in the eggcardboard behaving like Helmholtz resonators. In the case of sample 03, the peak around $700 \mathrm{~Hz}$ was very wide due to the presence of sound absorbing polyester fibers inside the main volume. This result suggests that to reach a good $T L$ it was important to arrange the egg boxes upside down, but they still had to be coupled with other materials to improve their performances. The presence of the holes improved the absorption characteristics.

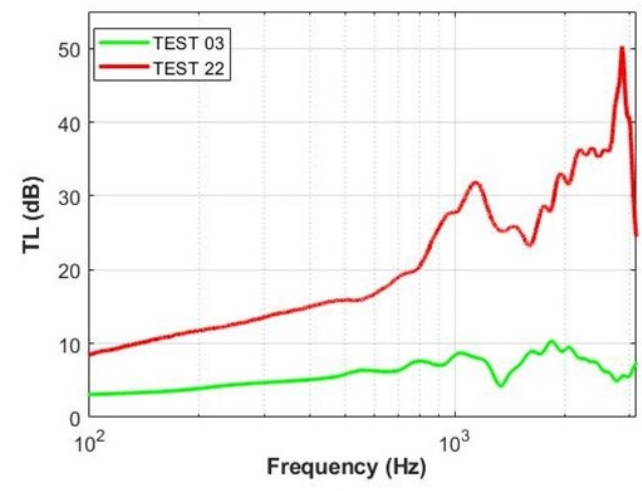

a)

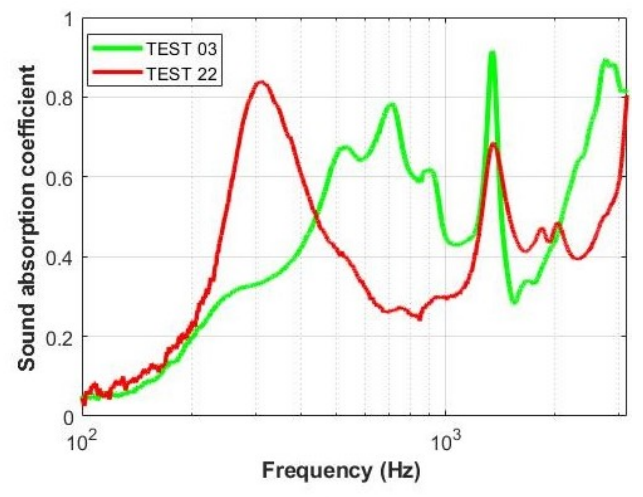

b)

Figure 9. Transmission loss (a) and absorption coefficient (b) of samples made of at least on egg-box and polyester.

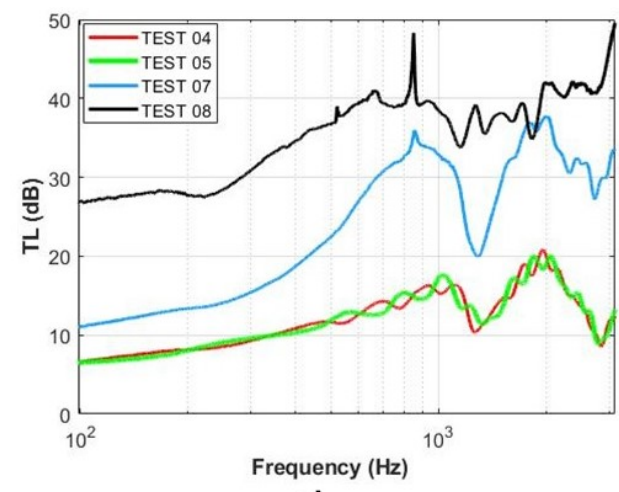

a)

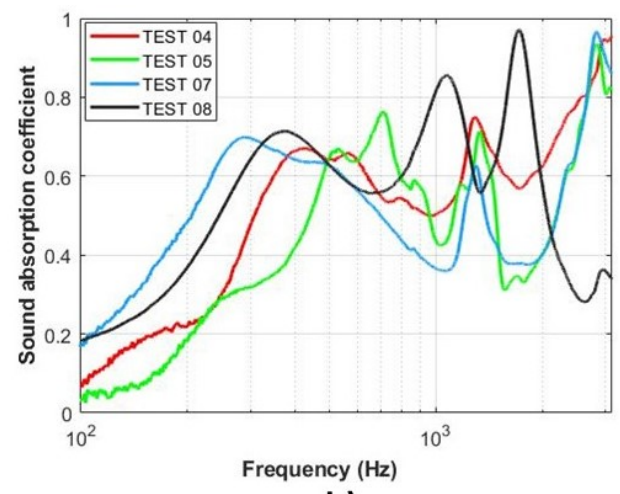

b)

Figure 10. Transmission loss (a) and absorption coefficient (b) of samples made of egg-box, cardboard, polyester and a metallic element. 


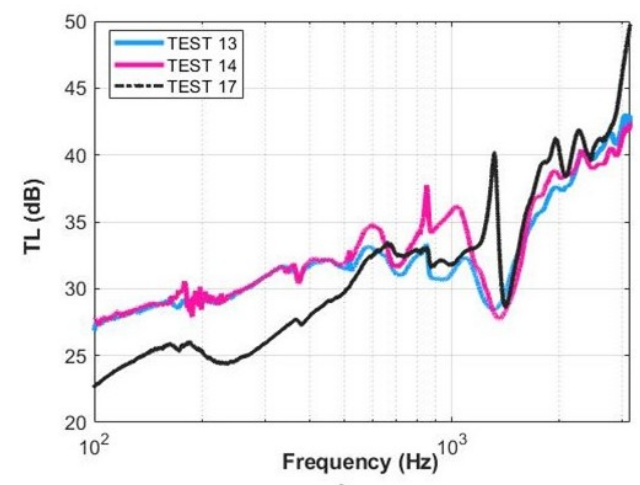

a)

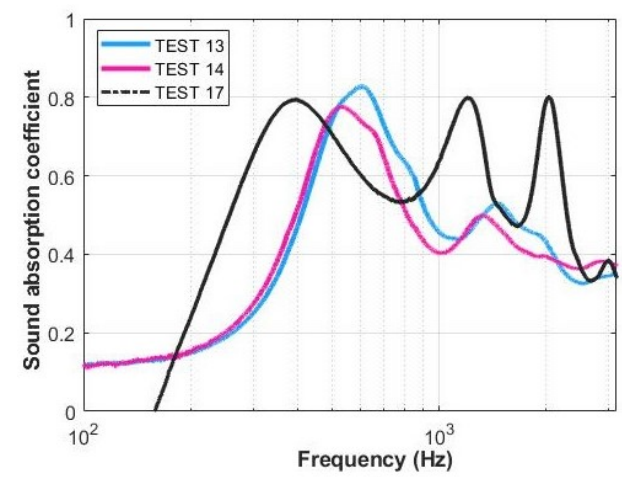

b)

Figure 11. Transmission loss (a) and absorption coefficient (b) of samples made of several layers of cardboard.

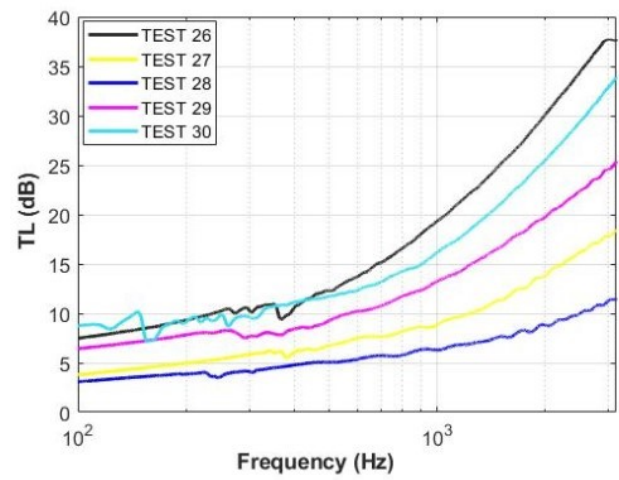

a)

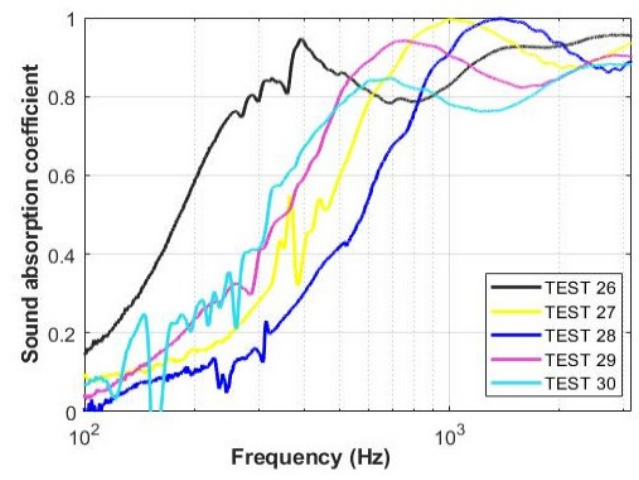

b)

Figure 12. Transmission loss (a) and absorption coefficient (b) of samples made of clothes (one fabric at a time).

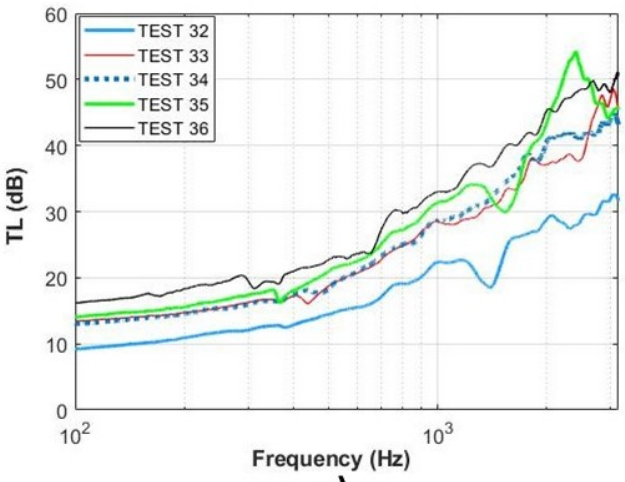

a)

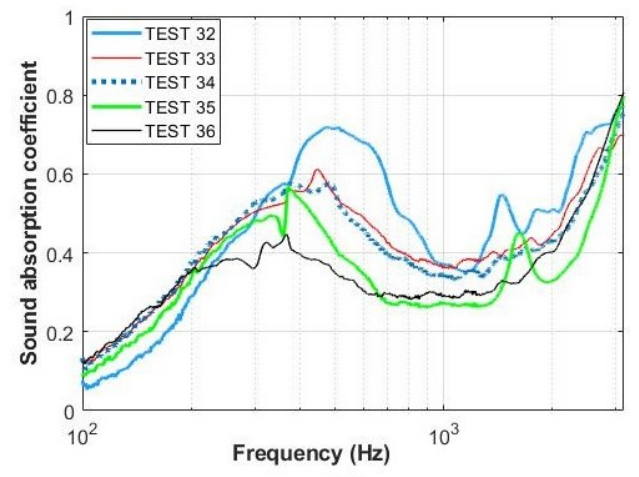

b)

Figure 13. Transmission loss (a) and absorption coefficient (b) of samples made of egg-boxes and clothes.

The $T L$ curves just analyzed were very similar to the curves obtained for the second set of samples and reported in Figure 10. This behavior can be explained by the nature of the samples which were built with the same elements: the egg-box, the polyester foam and steel spheres. The only variables were the orientation of the samples and the presence of a cardboard disk. The TLs of samples 04 and 05 were characterized by the typical mass law behavior due to the single egg cardboard, except a dip around $1200 \mathrm{~Hz}$. Samples 04 and 05 showed an interesting absorption coefficient, and sample 04 featured better performances 
since it did not present valleys at high frequency. However, since these samples were permeable to air, the $T L$ was very weak. Reducing the permeability, in samples 07 and 08 the additional cardboard layer caused an increase of the curve slope due to the massspring-mass behavior of the layers. Sample 08 exhibited very interesting performances at low frequencies and the highest $T L$ of the group also at high frequencies. In sample 08 the additional perforated cardboard layer facing the sound source captured sound energy at some specific frequency bands. Part of the energy that passed through the egg-box was absorbed by the fibrous material. Finally, the final last cardboard reduced the transmitted energy. For these samples, the absorption coefficient was characterized by multiple peaks typical of the resonators featured in the cardboard portions. The width of the peaks depended again on the presence of polyester fibers. The best performance belonged to sample 08 , characterized by a rather good sound absorption coefficient also at high frequency, with a maximum of 0.95 at $2 \mathrm{kHz}$.

As regards the third set of samples, Figure 11 shows very similar $T L$ curves for all the samples. This group of TL was the highest among the entire group of tested materials. Such behavior is due to the high density of the samples that made the samples similar to sandwich materials featuring non compressible cores. For this reason the trend was characterized by a mass-law behavior followed by the typical coincidence dip. For samples 13 and 14, the sound absorption coefficient was marked out by a maximum around $600 \mathrm{~Hz}$ due to the resonance of the Helmholtz resonators featured in the cardboard. For sample 17, the graph of the sound absorption was very similar to the one of sample 08 (having a very similar structure), with three peaks reaching a value of 0.8 .

The results of the fourth set of test samples, which were made of fabrics, are shown in Figure 12. The absorption curves were similar for all the samples and typical of porous materials. The best performance was given by sample 30 having the highest density of the group. Additionally, sample 26 showed a good performance but since it was $100 \mathrm{~mm}$ thick it could not be directly compared with the other samples. However, this result shows that better performances could be achieved by increasing the thickness of the panels. Additionally, in this case, the sound absorption coefficient had a shape typical for porous materials, featuring an $S$ shape, with low values at low frequencies and values approaching 1 at high frequencies. By comparing the NRC measured for samples 26 and 27 and reported in Table 2, it emerged that the operator skills affected the acoustic performances of the panels. Indeed, even if the samples were made of the same material and the same $N R C$ should be obtained, a higher value of $N R C$ was measured for the thinner sample (26) and this is probably due to the assembling mode.

The fifth and last set of samples was a combination of fabrics, egg-boxes and metal parts. As can be observed in Figure 13, all the TL curves had very similar trends. If compared to the $T L$ in Figure 12, for samples 32-36, values were generally higher at low frequency due to the higher mass per unit area of the samples. Sample 36 had the best performances for this group and this is probably due to the fact that the metal element could vibrate because it was not in contact with the rigid egg-carton. As concerns the sound absorption coefficient, the behavior was dominated by the Helmholtz resonator featuring a peak around $400 \mathrm{~Hz}$ followed by an increase of the coefficient due to the presence of the tissues.

\section{Conclusions}

The study presented in this paper has shown that EoLHM, such as cardboard, eggboxes, clothes and metal elements, can be reused to realize low-cost acoustic panels for the improvement of the indoor comfort. Since these panels are easy realizable and cheap, they can be used in disadvantaged contexts where low-income people live and can not afford commercial acoustic panels. By wisely coupling EoLHM, good acoustic performances can be obtained for panels of limited thickness. Measurements performed with the impedance tube technique have shown that samples made of fabrics present a sound absorption coefficient greater than 0.8 in the range $300-3500 \mathrm{~Hz}$. The higher insulation performance has been measured for samples made of perforated cardboard that present a $T L$ of 
$25-30 \mathrm{~dB}$ in the range $100-300 \mathrm{~Hz}$, and $30-40 \mathrm{~dB}$ in the range $300-2000 \mathrm{~Hz}$. To reach interesting performances from both the insulation and the absorption point of view, it is necessary to couple egg-cartons, cardboard, polyester and metal elements. For this configuration, $N R C$ is higher than 0.54 and the $T L$ varies between 25 and $40 \mathrm{~dB}$ in the range $250-2000 \mathrm{~Hz}$. Since in this study only the performance related to normal waves has been analyzed, in future investigation the most performing configurations will be tested in a reverberation room. Since the acoustic panels will be realized by not-skilled personnel and the manual skills affect the panels acoustic performance, it will be necessary to provide courses and guidelines for illustrating how the panels must be realized and installed.

Author Contributions: All authors conceived the presented idea. M.N. and E.L. designed the experimental campaign and wrote the paper with input from all authors. All authors have read and agreed to the published version of the manuscript.

Funding: The authors would like thank the Department of Mechanical and Industrial Engineering of University of Brescia for funding the research through the MetATer PRD project.

Acknowledgments: All the authors would like to thank the Applied Acoustics Laboratory of University of Brescia and Edoardo Alessio Piana for the opportunity to carry out the experimental tests and for the support in designing the experimental campaign.

Conflicts of Interest: The authors declare no conflict of interest.

\section{References}

1. United Nations. Transforming Our World: The 2030 Agenda for Sustainable Development. Available online: https:// sustainabledevelopment.un.org/post2015/transformingourworld/publication (accessed on 2 March 2021).

2. Lagonigro, R.; Martori, J.C.; Apparicio, P. Environmental noise inequity in the city of Barcelona. Transp. Res. Part D Transp. Environ. 2018, 63, 309-319. [CrossRef]

3. Moreno-Jiménez, A.; Cañada-Torrecilla, R.; Vidal-Domínguez, M.J.; Palacios-García, A.; Martínez-Suárez, P. Assessing environmental justice through potential exposure to air pollution: A socio-spatial analysis in Madrid and Barcelona, Spain. Geoforum 2016, 69, 117-131. [CrossRef]

4. Chiesura, A. The role of urban parks for the sustainable city. Landsc. Urban Plan. 2004, 68, 129-138. [CrossRef]

5. Rasmussen, B. Acoustic classification of buildings in Europe-Main characteristics of national schemes for housing, schools, hospitals and office buildings. In Proceedings of the Euronoise, Crete, Greece, 27-31 May 2018.

6. Kryter, K.D. The Effects of Noise on Man; Academic Press: New York, NY, USA, 1985.

7. European Parliament and the Council of the European Union. Directive 2002/49/EC of the European Parliament and of the Council of 25 June 2002 Relating to the Assessment and Management of Environmental Noise. Available online: http: / / eur-lex.europa.eu/legalcontent/EN/TXT/PDF/?uri=CELEX:32002L0049\&from=EN (accessed on 8 April 2021).

8. European Parliament and the Council of the European Union. Decision No 1386/2013/EU of the European Parliament and of the Council of 20 November 2013 on a General Union Environment Action Programme to 2020 Living Well, within the Limits of Our Planet. Available online: https:/ / eur-lex.europa.eu/eli/dec/2013/1386/oj (accessed on 26 April 2021).

9. UNIDO-United Nations Industrial Development Organization. Circular Economy. Available online: https://www.unido.org/ our-focus-cross-cutting-services / circular-economy (accessed on 15 May 2020).

10. Common Objective. Sustainability Issues-How Sustainable Is Paper and Cardboard Packaging? Available online: www. commonobjective.co/article/how-sustainable-is-paper-and-cardboard-packaging (accessed on 26 February 2021).

11. Chua, J.C. Asos, H\&M Seek to Keep Ancient, Endangered Forests Out of Packaging. Available online: https://sourcingjournal. com/topics / sustainability / canopy-pack4good-ecommerce-packaging-sustainable-recycled-asos-hm-kontoor-vf-172028 / (accessed on 31 March 2021).

12. Ritchie, H.; Roser, M. Plastic Pollution. Available online: https:/ / ourworldindata.org/plastic-pollution (accessed on 31 March 2021).

13. Beall, A. Why Clothes Are so Hard to Recycle. Available online: https://www.bbc.com/future/article/20200710-why-clothesare-so-hard-to-recycle (accessed on 13 July 2020).

14. Ellen MacArthur Foundation. A New Textile Economy: Redesigning Fashion's Future. Available online: www. ellenmacarthurfoundation.org (accessed on 31 March 2021).

15. Neri, M.; Pilotelli, M.; Traversi, M.; Levi, E.; Piana, E.A.; Bannó, M.; Cuerva, E.; Pujadas, P.; Guardo, A. Conversion of End-ofLife Household Materials into Building Insulating Low-Cost Solutions for the Development of Vulnerable Contexts: Review and Outlook towards a Circular and Sustainable Economy. Sustainability 2021, 13. [CrossRef]

16. European Parliament and Council of the European Union. Directive 2010/31/EU of the European Parliament and of the Council of 19 May 2010 on the Energy Performance of Buildings. Available online: https:/ / eur-lex.europa.eu/LexUriServ/LexUriServ. do?uri=OJ:L:2010:153:0013:0035:en:PDF (accessed on 26 April 2021). 
17. European Parliament and Council of the European Union. Directive 2012/27/EU of the European Parliament and of the Council of 25 October 2012 on Energy Efficiency, Amending Directives 2009/125/EC and 2010/30/EU and Repealing Directives 2004/8/EC and 2006/32/EC. Official Journal of the European Union, L 315, 14 November 2012. Available online: https:/ / eur-lex.europa.eu/ LexUriServ/LexUriServ.do?uri=OJ:L:2012:315:0001:0056:en:PDF (accessed on 29 April 2021).

18. Taaffe, J.; O'Sullivan, S.; Rahman, M.E.; Pakrashi, V. Experimental characterisation of Polyethylene Terephthalate (PET) bottle Eco-bricks. Mater. Des. 2014, 60, 50-56. [CrossRef]

19. ASTM C423-Complete Document Standard Test Method for Sound Absorption and Sound Absorption Coefficients by the Reverberation Room Method; ASTM International: West Conshohocken, PA, USA, 2017.

20. Cao, L.; Fu, Q.; Si, Y.; Ding, B.; Yu, J. Porous materials for sound absorption. Compos. Commun. 2018, 10, 25-35. [CrossRef]

21. Arenas, J.; Crocker, M. Recent trends in porous sound-absorbing materials. Sound Vib. 2010, 44, 12-17.

22. Delany, M.E.; Bazley, E.N. Acoustical properties of fibrous absorbent materials. Appl. Acoust. 1970, 3, 105-116. doi:10.1016/0003682X(70)90031-9 [CrossRef]

23. Oldham, D.J.; Egan, C.C.R. Sustainable acoustic absorbers from the biomass. Appl. Acoust. 2011, 72, 350-363. doi:10.1016/j.apacoust.2010.12.009 [CrossRef]

24. Wang, Y.H.; Zhang, C.C.; Ren, L.Q.; Ichchou, M.; Galland, M.A.; Bareille, O. Sound absorption of a new bionic multi-layer absorber. Compos. Struct. 2014, 108, 400-408. [CrossRef]

25. Pelegrinis, M.T.; Horoshenkov, K.V.; Burnett, A. An application of kozeny-carman flow resistivity model to predict the acoustical properties of polyester fibre. Appl. Acoust. 2016, 101,1-4. [CrossRef]

26. Othmani, C.; Taktak, M.; Zein, A.; Hentati, T.; Elnady, T.; Fakhfakh, T.; Haddar, M. Experimental and theoretical investigation of the acoustic performance of sugarcane wastes based material. Appl. Acoust. 2016, 109, 90-96. [CrossRef]

27. Meric, C.; Erol, H.; Ozkan, A. On the sound absorption performance of a felt sound absorber. Appl. Acoust. 2016, 114, 275-280. [CrossRef]

28. Langfeldt, F.; Hoppen, H.; Gleine, W. Resonance frequencies and sound absorption of Helmholtz resonators with multiple necks. Appl. Acoust. 2019, 145, 314-319. [CrossRef]

29. Nilsson, A.; Baro, S.; Piana, E.A. Vibro-acoustic properties of sandwich structures. Appl. Acoust. 2018, 139, 259-266. [CrossRef]

30. Piana, E.; Nilsson, A. Prediction of the sound transmission loss of sandwich structures based on a simple test procedure. In Proceedings of the 17th International Congress on Sound and Vibration 2010, ICSV 2010, Cairo, Egypt, 18-22 July 2010; International Institute of Acoustics and Vibrations, IIAV: Cairo, Egypt, 2010; Volume 1, pp. 109-116.

31. Piana, E.; Petrogalli, C.; Solazzi, L. Dynamic and acoustic properties of a joisted floor. In Proceedings of the SIMULTECH 2016-International Conference on Simulation and Modeling Methodologies, Technologies and Applications, Lisbon, Portugal, 29-31 July 2016; Obaidat, M., Merkuryev, Y., Oren, T., Eds.; SciTePress: Lisbon, Portugal, 2016; pp. $277-282$.

32. Bruel \& Kjaer. Measurements in Building Acoustics; Bruel \& Kjaer: Nærum, Denmark, 1998.

33. Iannace, G.; Umberto, B.; Bravo-Moncayo, L.; Ciaburro, G.; Puyana-Romero, V. Organic waste as absorbent materials. In Proceedings of the 2020 International Congress on Noise Control Engineering, INTER-NOISE 2020, Seoul, Korea, 23-26 August 2020.

34. Lee, Y.; Joo, C. Sound absorption properties of recycled polyester fibrous assembly absorbers. Autex Res. J. $2003,3,139-146$.

35. Saravana Kumar, T.; Ramesh Kumar, M. Development of needle punched non-woven fabrics for acoustic application. Int. J. ChemTech Res. 2015, 8, 21-26.

36. Lyu, L.; Li, C.; Wang, Y.; Lu, J.; Guo, J. Sound absorption, thermal, and flame retardant properties of nonwoven wall cloth with waste fibers. J. Eng. Fibers Fabr. 2020, 15. [CrossRef]

37. Trajković, D.; Jordeva, S.; Tomovska, E.; Zafirova, K. Polyester apparel cutting waste as insulation material. J. Text. Inst. 2017, 108, 1238-1245. [CrossRef]

38. Asami, T.; Miura, H. Basic study of the acoustic characteristics of cotton fabric with differing moisture content using $28 \mathrm{kHz}$ ultrasound. Jpn. Appl. Phys. 2019, 58, SGGD08. [CrossRef]

39. Asdrubali, F.; Pisello, A.L.; D'Alessandro, F.; Bianchi, F.; Cornicchia, M.; Fabiani, C. Innovative cardboard based p anels with recycled materials from the packaging industry: Thermal and acoustic performance analysis. Energy Procedia 2015, 78, 321-326. [CrossRef]

40. Secchi, S.; Asdrubali, F.; Cellai, G.; Nannipieri, E.; Rotili, A.; Vannucchi, I. Experimental and environmental analysis of new sound-absorbing and insulating elements in recycled cardboard. J. Build. Eng. 2015, 5, 1-12. [CrossRef]

41. Paternoster, A.; Van Camp, J.; Vanlanduit, S.; Weeren, A.; Springael, J.; Braet, J. The performance of beer packaging: Vibration damping and thermal insulation. Food Packag. Shelf Life 2017, 11, 91-97. [CrossRef]

42. Kang, C.W.; Kim, M.; Jang, E.S.; Lee, Y.H.; Jang, S.S. Sound absorption coefficient and sound transmission loss of porous sponge attached corrugated cardboard of noise insulation cover. Palpu Chongi Gisul/J. Korea Tech. Assoc. Pulp Pap. Ind. 2020, 52, 38-44. [CrossRef]

43. Jun-Oh, Y.; Kyoung-Woo K.; Kwan-Seop, Y.; Jea-Min, K.; Myung-Jun, K. Physical properties of cellulose sound absorbers produced using recycled paper. Constr. Build. Mater. 2014, 70, 494-500. [CrossRef]

44. Shoubi, M.V.; Shoubi, M.V.; Barough, A.S. Investigating the Application of Plastic Bottle as a Sustainable Material in the Building Construction. Int. J. Sci. Eng. Technol. Res. (IJSETR) 2013, 2, 28-34.

45. Iannace, G.; Ciaburro, G. Modelling sound absorption properties for recycled polyethylene terephthalate-based material using Gaussian regression. Build. Acoust. 2020. [CrossRef] 
46. Patnaik, A.; Mvubu, M.; Muniyasamy, S.; Botha, A.; Anandjiwala, R.D. Thermal and sound insulation materials from waste wool and recycled polyester fibers and their biodegradation studies. Energy Build. 2015, 92, 161-169. [CrossRef]

47. Iwase, T.; Sugie, S.; Kurono, H.; Abe, M.; Okada, Y.; Yoshihisa, K. Sound absorption characteristic of glass and plastic bottles: Considerations of their dependences on material properties. In Proceedings of the ASME 2018 Noise Control and Acoustics Division Session Presented at INTERNOISE 2018, Chicago, IL, USA, 26-29 August 2018; [CrossRef]

48. Viegas, L.; Bezerra, U.; Barbosa, N. Blocks for Performance of Masonry Using PET Bottle Seal: Thermal, acoustic, and Mechanical and evaluation. Key Eng. Mater. 2014, 600, 753-767. [CrossRef]

49. Kassim, U.; Goh, J.K.S. Recycle materials as industrialised building system (IBS) internal partition. J. Built Environ. Technol. Eng. 2016, 1, 330-334. ISSN 0128-1003.

50. Satwiko, P.; Gharata, V.D.; Setyabudi, H.; Suhedi, F. Enhancing egg cartons' sound absorption coefficient with recycled materials. Build. Acoust. 2017, 24, 115-131. [CrossRef]

51. Quintero-Rincon, A. Measurement of the sound-absorption coefficient on egg cartons using the Tone Burst Method. In Proceedings of the 11th WSEAS International Conference on Acoustics and Music: Theory and Applications, AMTA 10, Iasi, Romania, 13-15 June 2010.

52. Carvalho, A.P.O.; Vieira, S.C.P. Sound absorption of egg boxes and trays. In Proceedings of 44th International Congress and Exposition on Noise Control Engineering, San Francisco, CA, USA, 9-12 August 2015.

53. Iannace, G.; Berardi, U.; Ciaburro, G.; Trematerra, A. Egg cartons used as sound absorbing systems. In Proceedings of the INTER-NOISE and NOISE-CON Congress and Conference Proceedings, Seoul, Korea, 23-26 August 2020.

54. Sim J.; Zulkifli, R.; Tahir, M.; Khidir, E.. Recycled paper fibres as sound absorbing material. Appl. Mech. Mater. 2014, 663, 459-463. [CrossRef]

55. ASTM E2611 Standard Test Method for Normal Incidence Determination of Porous Material Acoustical Properties Based on the Transfer Matrix Method; ASTM International: West Conshohocken, PA, USA, 2019.

56. Kassim, U.; Goh, J. Acoustic Myths and Realities: Can Egg Carton Be Used as an Acoustical Treatment? Available online: http:/ / www.acousticsfirst.com/eggc.htm (accessed on 29 April 2021). 